\title{
Sobre a tradução da Ethica Eudemia por Anthony Kenny
}

André Luiz Cruz Sousa (Universidade Federal do Rio Grande do Sul (UFRGS), Porto Alegre, Brasil)

andreluizcrs@gmail.com

\section{Obras analisadas}

A tradução objeto da resenha é a seguinte:

KENNY, A. 2011. The Eudemian Ethics. Translated with an introduction and notes by Anthony Kenny. Oxford World's Classics.

Outras traduções são citadas pontualmente com intuito de comparação:

BONET, J. P. 1993. Ética Nicomáquea/Ética Eudemia. Traducción y notas por Julio Pallí Bonet. Madrid: Editorial Gredos.

DIRLMEIER, F. 1957. Nikomachische Ethik. Übersetzt, eingeleitet und kommentiert von Franz Dirlmeier. Frankfurt am Main und Hamburg: Fischer Bücherei.

ROSS, W.D. 1998. The Nicomachean Ethics. Translated with an Introduction by David Ross. Revised by J. L. Ackrill and J.0. Urmson. Oxford World's Classics.

SOLOMON, J. 1984. Eudemian Ethics. Translated by J. Solomon. In: BARNES, Jonathan. The Complete Works of Aristotle. Volume two. Princeton University Press.

Os demais textos são as edições do texto grego de Aristóteles, bem como textos de outros autores: BYWATER, I. 1894. Aristotelis Ethica Nicomachea. Oxford Classical Texts. 
KENNY, A. 1978. The Aristotelian Ethics: a study of the relationship between the Eudemian and the Nicomachean Ethics of Aristotle. Oxford: Clarendon Press. 1992. Aristotle on the Perfect Life. Oxford: Clarendon Press.

WALZER et MINGAY. 1991. Aristotelis Ethica Eudemia. Oxford Classical Texts.

\section{Perspectiva geral}

A tradução inglesa recentemente publicada da Ethica Eudemia é merecedora de atenção cuidadosa dos filósofos dedicados ao estudo de Aristóteles por uma razão apontada pelo autor (KENNY, 2011, p. xxviii): “a Ethica Eudemia aparece, pela pri-meira vez em uma língua moderna, de forma completa e não truncada". Em outras palavras, a tradução inclui tanto aqueles livros que constituem o núcleo distintivo da Ethica Eudemia em contraposição à Ethica Nicomachea - EE I, II, III, VII e VIII - quanto os livros tradicionalmente atribuídos a ambos os tratados, mas publicados pre-ferencialmente como parte da Ethica Nicomachea, a saber, os livros que tratam da justiça, das virtudes dianoéticas e da continência e incontinência, respectivamente V, VI e VII da Ethica Nicomachea ou IV, V e VI da Ethica Eudemia.

A decisão de publicar uma tradução da Ethica Eudemia na qual estão inclusos os livros "comuns" pode ser vista como uma reivindicação do valor do tratado, que na tradução de Kenny surge como autossuficiente na medida em que contém a totalidade da temática da ética aristotélica encontrada nas inúmeras edições da Ethica Nicomachea: uma discussão preliminar sobre a felicidade, uma discussão geral sobre a virtude (contendo tópicos como a mediania, o voluntário e a escolha), uma discussão específica a respeito de cada virtude - ética ou dianoética - uma discussão sobre a relação entre virtude e prazer, uma discussão sobre a amizade, e uma discussão a respeito da relação entre ação moral e contemplação filosófica como conteúdos da vida feliz. Kenny oferece ao leitor uma versão da Ethica Eudemia que pode ser, de fato, cotejada com a Ethica Nicomachea em condição de igual importância por aquele que pretenda compreender a Ética de Aristóteles em sua integralidade. As traduções que excluem os livros comuns, por razões teoréticas (o tradutor entende que os livros comuns pertencem de fato à Ethica Nicomachea) ou simplesmente editoriais (o tradutor pensa que leitor pode encontrar os livros comuns nas inúmeras edições da Ethica Nicomachea), acabam por tornar a compreensão da Ethica Eudemia - incompleta e, conse-quentemente, fragmentária - parasitária em relação à Ethica Nicomachea.

0 cunho reivindicativo transparece na narrativa, que o autor realiza na Introdução ( $p$. $\mathrm{x}$-xi), da progressiva perda de estima do tratado da Ethica Eudemia frente ao seu par mais famoso, desde a sua proeminência nos catálogos da e comentários à obra de Aristóteles 
logo após a sua morte, até a posição de coadjuvante a partir do comentário de Aspásio à Ethica Nicomachea no segundo século da Era Cristã, posição reforçada pela desvantagem no número de manuscritos da Eudemia em relação à Nicomachea no período bizantino e pela tradução completa da última para o latim em detrimento da tradução de poucos fragmentos da primeira. A trajetória de derrocada culminou na consideração da Ethica Eudemia como tratado espúrio no século XIX, condição que foi mitigada quando ela passou a ser vista como um tratado autêntico, porém imaturo, inferior nesse sentido ao trabalho supostamente mais acabado da Ethica Nicomachea. Em contraposição a essa vertente, Kenny menciona na introdução sua tese segundo a qual os livros tidos como comuns pertencem de fato à Ethica Eudemia, com base em argumentos desenvolvidos anteriormente em seus textos The Aristotelian Ethics (KENNY, 1978) e Aristotle on the Perfect Life (KENNY, 1992): a consequência desse argumento é que a presente tradução deve ser compreendida no contexto de uma interpretação da obra de Aristóteles na qual a Ethica Eudemia possui primazia entre os textos de filosofia moral ${ }^{1}$.

\section{Dos aspectos formais e da natureza da tradução}

A base da tradução, no que diz respeito aos livros que perfazem exclusivamente a Ethica Eudemia, é o texto grego da 0xford Classical Texts (OCT) editado por R. Walzer e J. Mingay. Quanto aos livros tradicionalmente tidos como comuns, a tradução se baseia no texto da Ethica Nicomachea da OCT editado por I. Bywater. A tradução mantém a paginação Bekker, resultando em curiosa ordenação: páginas 1214a1-1234b14 para os livros I-III, 1129a3-1154b34 para os livros IV-VI, e 1234b18-1249b25 para os livros VI-VIII. Kenny mantém, igualmente, a divisão em capítulos existente em Bekker e opta pelo hábito, comum a muitos tradutores, de atribuir subtítulos aos mesmos.

No que diz respeito ao estilo, a tradução é apresentada como almejando captar o sentido do texto grego sem deter-se à ordenação das frases dos manuscritos gregos ou à pontuação acrescida pelos editores da OCT: o tradutor pretende "produzir um inglês claro e legível, mais preocupado em preservar a opinião de Aristóteles do que obter uma correspondência palavra-palavra com o original" (KENNY, 2011, p. xxix). Dado o caráter esquemático dos textos aristotélicos, cuja concisão não decorre da intenção deliberada de produzir ambiguidade - Kenny afirma, com razão, que "aquilo que nos foi transmitido de Aristóteles ao longo dos séculos é antes um conjunto de telegramas do que de epístolas" (2011, p. ix) - parece de fato pouco interessante a opção por uma tradução mais literal cuja vantagem seria preservar o equilíbrio entre velar e desvelar característico de textos como os diálogos de Platão. 
0 fato do pensamento de Aristóteles estar em regra expresso textualmente na forma de esboços em uma língua capaz de expressar pensamentos complexos com economia de palavras implica um desafio ao tradutor, pois para expressar o pensamento do filósofo a tradução precisa ser, em alguma medida, interpretativa: "é necessário esforço para decodificar a mensagem dos enunciados irregulares" (KENNY, 2011, p. viii-ix). Uma tradução literal poderia revelar a humildade do tradutor, que não quer arriscar-se a distorcer o pensamento de Aristóteles. Entretanto, os enunciados vagos em uma língua moderna qualquer, aos quais essa tradução literal inevitavelmente recorrerá, não são capazes de exprimir aquilo que a língua grega expressa de modo elíptico. A sequência de enunciados truncados tornaria a respectiva tradução irrelevante enquanto instrumento para a compreensão do pensamento de Aristóteles. Ao produzir uma tradução menos literal e mais interpretativa, Kenny torna sua obra suscetível ao risco da distorção, porém significativa para a exegese do pensamento do Estagirita.

\section{Observações a respeito da tradução}

0 conjunto de observações que se segue, de modo algum um exame exaustivo da tradução, volta-se para os respectivos pontos: primeiro trata das opções do tradutor ao verter para 0 inglês alguns dos termos centrais do tratado; em seguida examina algumas passagens dos livros I e VIII que são relevantes para a estrutura do argumento central da Ethica Eudemia, a saber, o conceito de عủठaııovía.

0 livro V, sobre as virtudes dianoéticas (livro VI na Ethica Nicomachea), confere a Kenny a melhor oportunidade para exercer uma tradução que interpreta conceitos idiomáticos e expressões elípticas do grego antigo de modo a permitir ao leitor moderno uma compreensão acurada sobre aquilo que Aristóteles ensina. A opção do tradutor, que tem a virtude de tornar claros conceitos característicos do modo de vida grego através de palavras que não acarretam uma compreensão contraintuitiva do idioma moderno, é notável em 1139b15-17.

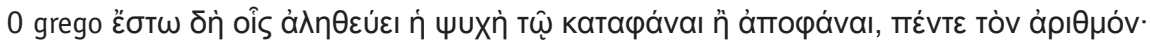

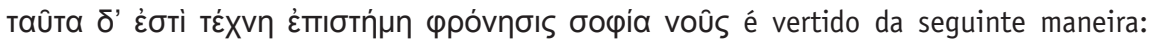
"There are, let us say, five distinct states in which the soul attains truth by affirmation or denial, namely, art, knowledge, wisdom, understanding, and intelligence" (KENNY, 2011,

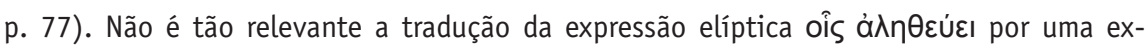
pressão mais extensa que explica que se trata de estados ou condições nos quais algo (no caso a alma) alcança a verdade, o que outros tradutores obtêm ${ }^{3}$, mas o modo como Kenny opta por verter os cinco estados através de termos únicos, evitando expressões compostas 
contra-intuitivas: ao fazê-lo, ele não apenas forja o inglês como língua filosófica, como permite ao leitor moderno acessar com precisão a realidade da qual trata Aristóteles.

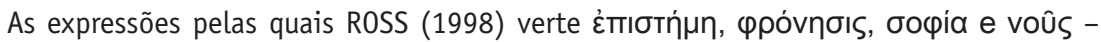
sicentific knowledge, practical wisdom, philosophic wisdom, intuitive reason ${ }^{4}$ - acabam por forjar uma linguagem técnica que afugenta a compreensão natural da língua moderna, como se a realidade articulada por Aristóteles não mais existisse entre nós. 0 resultado dessa tradução é um texto distante tanto da experiência do grego antigo quanto da experiência do leitor moderno. Nesse sentido, a tradução "scientific knowledge" expressa corretamente aquilo que Aristóteles designa por غ̇ாıбтń n em Ethica Eudemia V (ou Ethica Nicomachea VI), a saber, a apreensão pela razão de um aspecto da realidade que "consideramos não ser

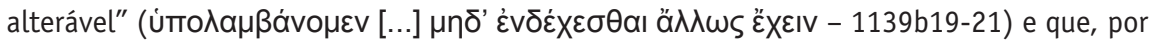
essa razão, "é acompanhada de demonstração" ( tradução tira do alcance do leitor moderno é que o filósofo designa a condição do homem que possui ciência por meio de um emprego estrito do termo grego cujo emprego amplo designa a condição de quem possui um conhecimento qualquer ${ }^{5}$. Nesse sentido, o conheci-

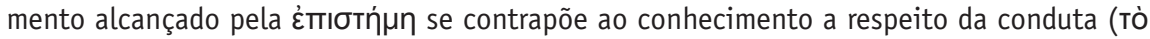

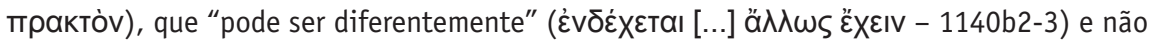
admite demonstração.

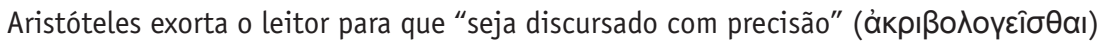

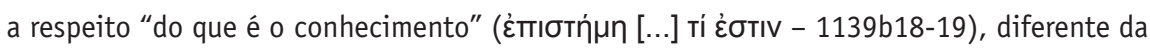
concessão que fizera em Ethica Eudemia I, quando aceitara, com hesitação, nivelar "todas

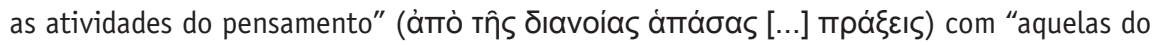

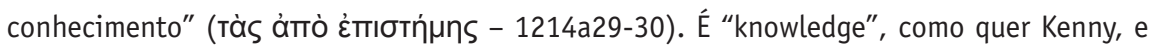
não "scientific knowledge", como quer Ross, que necessita de uma compreensão mais específica. Essa demarcação do âmbito de uma dada atividade para distingui-la de outras designadas por um uso mais amplo de uma mesma palavra é expressa na tradução, por Kenny, de тò દ̇тıбтптóv por "what is known", ao invés do desnecessário "the object of scientific

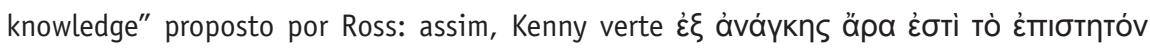
(1139b22-23) para "whatever is known, therefore, is necessary".

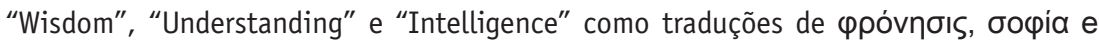
voûs também representam um ganho de compreensão ofertado por Kenny em relação às opções de Ross (Practical Wisdom, Philosophic wisdom e Intuitive Reason). Reservar a designação "sabedoria" (wisdom) para a condição do homem que pos-sui experiência quanto à ação moral não só está em concordância com a compreensão usual da palavra (não usamos a palavra sábio ou o equivalente inglês 'wise' a fim de nomear alguém com conhecimento específico, mas principalmente para nomear alguém que é visto como uma referência 
em questões morais ${ }^{6}$ ) como evita a confusão, à qual o leitor de Ross está suscetível, entre uma sabedoria que seria prática (practical wisdom) e outra que seria teórica (philosophi-

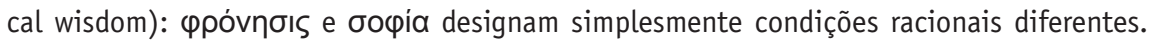
"Intelligence" como tradução de voûs é igualmente uma opção que favorece o uso natural e intuitivo da língua moderna: por que não chamar "inteligência" aquela condição que permite ao homem captar de modo imediato aquilo que não pode ser demonstrado, mas que é o princípio inerente ao que é conhecido de modo necessário? "Understanding" como tradução de бoчía, embora melhor do que o tradicional "philosophic wisdom", é menos intuitivo que as demais escolhas de Kenny, como mostra a decisão do autor de traduzir ó бọó s por "people who possess understanding" (KENNY, 2011, p.80). No entanto, dado que a бopía

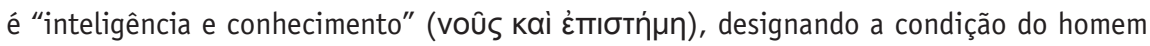

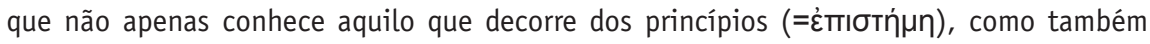
possui a verdade quanto aos princípios (=voû $)^{7}$, não produz confusão afirmar que esse homem "entende" aquele aspecto da realidade que é por necessidade, em distinção daquele homem que apenas "conhece" esse aspecto sem acessar os princípios. Nesse sentido, tò бофóv, traduzido por Kenny como "what is understood", representa um aprimoramento da

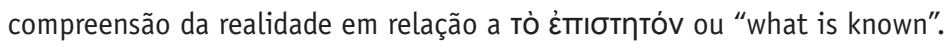

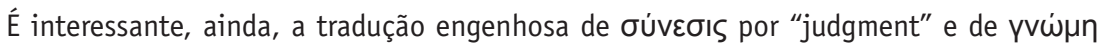

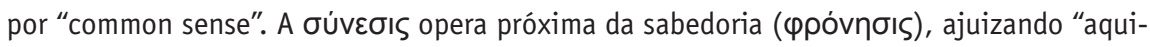

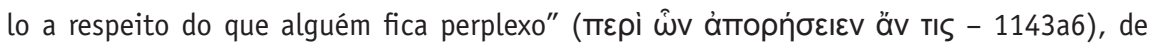
modo que essa capacidade do sábio em compreender uma situação singularíssima é melhor captada como "judgment", como quer Kenny, do que como "understanding", como quer

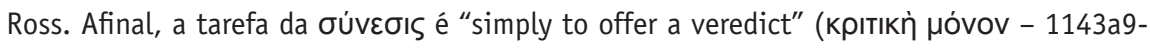

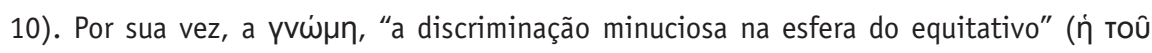

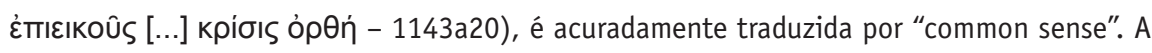

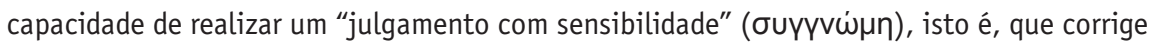
uma aplicação estrita de uma regra que teria resultado indesejado, não poderia ser melhor nomeada do que como "bom senso", cuja falta permitiria a alguém realizar a aplicação rígida da regra em questão.

Outro aspecto crucial da tradução diz respeito ao argumento central da Ethica Eudemia,

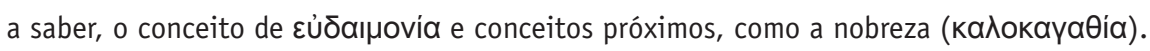
Deve ser destacada, por exemplo, a agudeza da tradução de 1248b18-20 por Kenny que, em virtude do que poderia parecer um detalhe sem importância, aprimora nossa compreensão do argumento que Aristóteles dedica à distinção entre ser bom (Tò áyaӨòv عîvaı) e ser

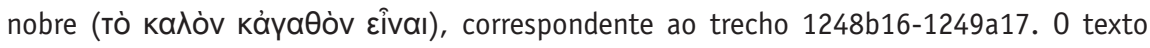

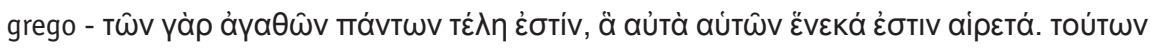




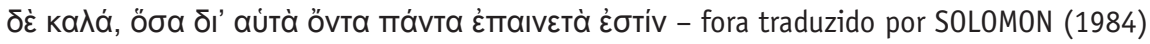
como "For all goods have ends which are to be chosen for their own sake. Of these, we call noble those which, existing all of them for their own sake, are praised"; Kenny propõe "Among all goods, some are ends that are valuable for their own sake; among these, some are noble, namely, those that are laudable for their own sake". A diferença entre o sentido dos trechos grifados, a saber, entre "elogiável" (દ̇maıvetóv) como atributo exclusivo dos fins nobres (como quer Solomon) e como atributo per se dos fins nobres, que repercute, porém, em outros fins (como quer Kenny), é a diferença entre, respectivamente, um argumento confuso e um argumento bem acabado.

A razão disso é que na sequência da frase em questão Aristóteles distingue, em um primeiro momento de forma drástica, os fins elogiáveis (virtude e ações virtuosas) dos fins bons, porém não-elogiáveis (saúde, força física), para em seguida relativizar a distinção por meio de variações na predicação da qualidade "nobre" (Kaגòv) de acordo com o caráter do homem. 0 resultado é uma hierarquia resumida em 1249a11-13: “Para os muitos [...] as coisas boas sem qualificação não são boas, para o homem bom são boas, e para o homem

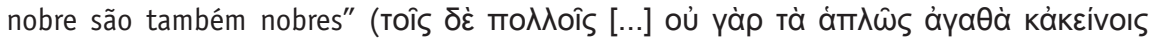

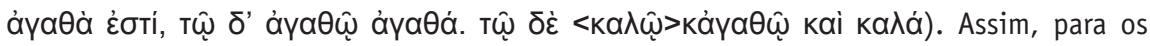

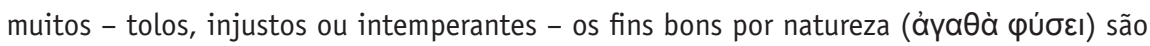
danosos ( $\beta \Lambda \alpha \beta \varepsilon \rho \alpha \dot{)}$ em virtude do seu caráter (1248b27-32). Para os homens bons, por sua vez, os bens por natureza são bons (1248b26-27), na medida em que seu caráter é virtuoso, mas não são nobres caso esses homens, como fazem os espartanos, almejem a virtude não por si mesma, mas tendo em vista os fins que são bons por natureza (1248b37-1249a2): “as

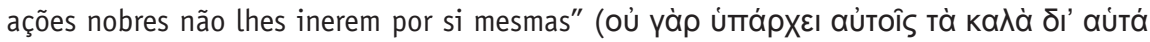
- 1249 a2-3). Já para os homens nobres, aqueles que escolhem praticar as ações nobres

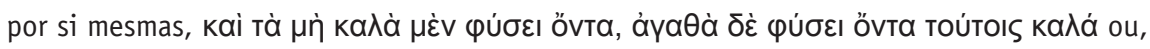
como traduz Kenny, "things that by nature are not noble but merely good become noble for them (KENNY, 2011, p. 147). A explicação para a diferença consta da frase seguinte:

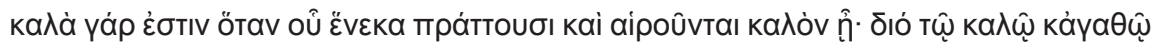

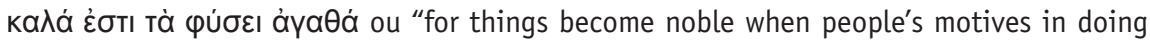
and choosing them are noble; and that is why to the noble person the natural goods are noble" (KENNY, 2011, p. 147).

Essa repercussão da predicação da nobreza, permitindo sua inerência acidental em bens por natureza apenas bons - saúde, força física, honra - esclarece a tradução correta

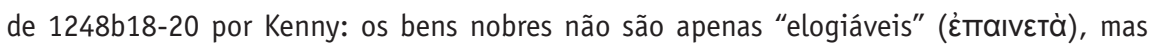

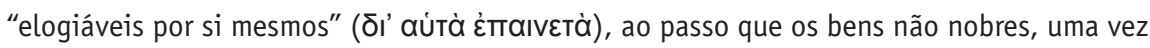
exercidos pelo homem nobre em vista de bens nobres, são acidentalmente nobres, portanto 


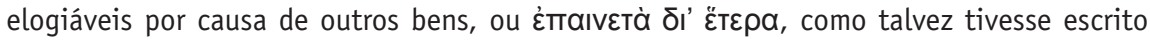
Aristóteles caso tivesse optado por um fraseado menos elíptico.

A respeito do conceito de عủठaııovía, cabe observar a tradução de trechos como Ethica Eudemia I.2, I.8 e VII.15/VIII.3, que revelam o desafio que o argumento principal do tratado representa para o tradutor. Em I.8 o filósofo discute aủió tò áyaӨòv ou "o bem em

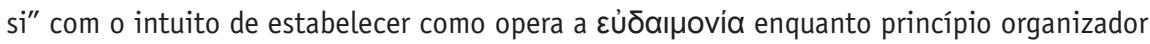
da vida humana. Tendo descartado a "ideia de bem" (ì ỉóca táyaӨoû) e o "bem comum" (тò Kolvóv áyaӨòv) como incapazes de explicar essa operação, Aristóteles apresenta o que

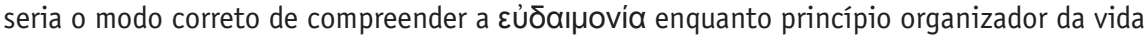

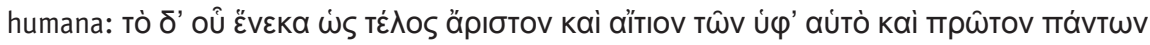
(1218b10-11). KENNY (2011, p.13) verte para o inglês: "the purpose or end that is the cause of what leads to it and is the first of all goods". Importa, aqui, aïrıov tûv ú $\varphi$ ' aúтò, traduzido pela expressão "the cause of what leads to it". A vagueza da expressão inglesa, que não afirma com clareza se aquilo que conduz ao propósito o integra ou se é um instrumento dele apartável, aponta a dificuldade em precisar aquilo em que consiste a teleologia segundo o Estagirita. Que essa precisão não é sem impacto na Ética o mostra o enuncia-

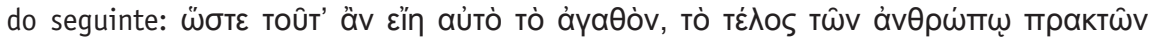
(1218b11-12) ou "it is this, then, that goodness itself must be: the end of everything attainable by human action" (KENNY, 2011, p. 13). Em outras palavras, aquilo que está na

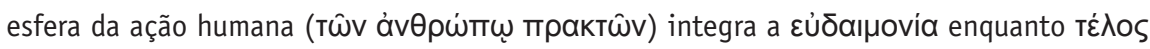

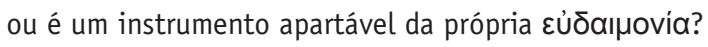

A vagueza da tradução desaparece algumas linhas adiante, mais precisamente em

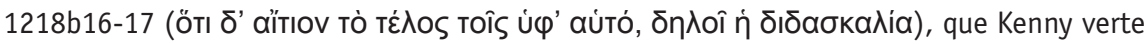
como "an end stands in a causal relation to the means subordinate to it: that is shown by the method of teaching" (KENNY, 2011, p.13). A opção por traduzir toîs ú $\varphi$ ' aútó como 'meios' está sujeita a críticas. 0 texto de Ethica Eudemia VII.15/VIII.3, a respeito da faculdade contemplativa (тò $\theta \varepsilon \omega \rho \eta$ тIKỏv), esclarece os contornos que essa interpretação da teleologia assume na Ética. Ali é afirmado que o deus ( $\theta \varepsilon$ cós), objeto da contemplação, é

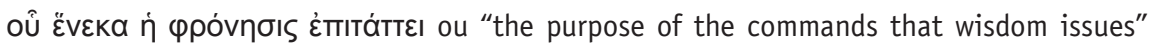
(KENNY, 2011, p.148). Se a proposta de Kenny a respeito de 1218b16-17 é acatada, a consequência é que os comandos da $\varphi$ póvnбıs (bem como seu exercício) são meios para a contemplação divina, que seria o "bem em si" (aủió tò áyaӨòv) enunciado em Ethica Eudemia I.8. Nesse caso a distinção entre a contemplação e o exercício da sabedoria no agir corresponderia à distinção proposta em Ethica Eudemia I.2 entre "aquilo em que consiste

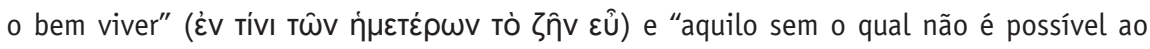

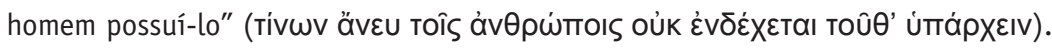




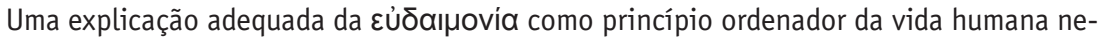

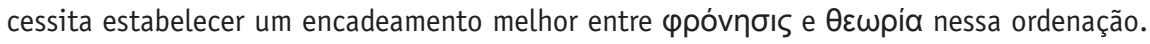
Afinal, o ‘bem em si' (aủró tò áyaӨòv) é, como traduz KENNY (2011, p. 13), “the object of the Science which is supreme over all others, namely political and economic science and

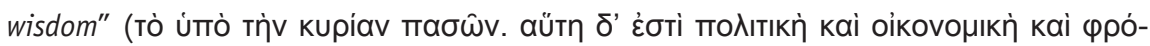

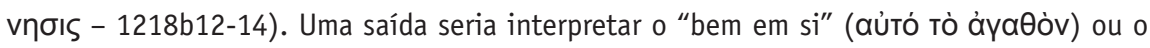

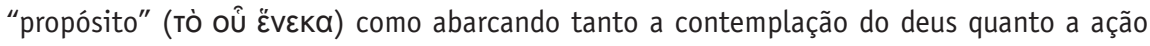
moral: nesse sentido, "aquilo em que consiste o bem viver" corresponderia a essas duas atividades, ao passo que "aquilo sem o qual não é possível ao homem possuí-lo" corresponderia àqueles bens que, em Ethica Eudemia VII.15/VIII.3, são ditos "bons por natureza, mas

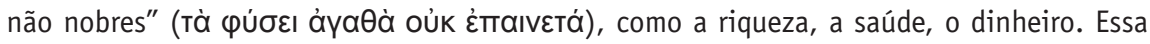
interpretação, embora plausível, não se sustenta nos termos da tradução de 1218b16-17 por Kenny: ela, por um lado, une a sabedoria e a contemplação no 'bem em si', em vista do qual tudo de-mais seria "meio", mas, por outro, ignora a distinção de nível entre sabedoria e con-templação no argumento supramencionado de Ethica Eudemia VII.15/VIII.3. Faz-se necessária uma explicação na qual a contemplação ( $\theta \varepsilon \omega \rho i ́ \alpha)$ seja raison d'être da sabedoria ( $\varphi \rho o ́ v \eta \sigma ı)$, sem que a última, porém, seja estabelecida como um "meio" para a primeira.

Essa explicação talvez seja possível se rejeitada a proposta de Kenny e adotada a tradução de aỉtıov Tûv ú $\varphi$ ' aúTò sugerida por SOLOMON (1984) tanto para 1218b10-11 quanto para 1218b16-17, a saber "cause of all that comes under it", o que permite a interpretação do 'bem em si' (тò áyaӨòv aủтó) como o ponto culminante de uma escala cujos constituintes não são, ao menos não todos, considerados instrumentos. Esse trajeto é sugerido por Aristóteles como o modo adequado de argumentar a respeito do 'bem em

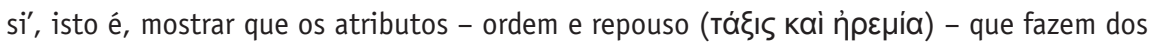
bens cujo estatuto enquanto tais é alvo de acordo - saúde, força física e temperança - são mais intensos nos entes imóveis (1218a21-24). Nesse sentido, poderíamos sugerir que 0

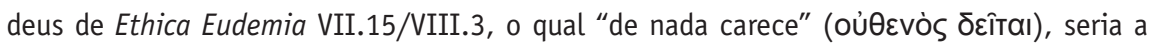
máxima ordenação e repouso existente, cuja perfeição serviria de modelo ao homem na

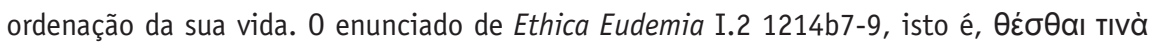

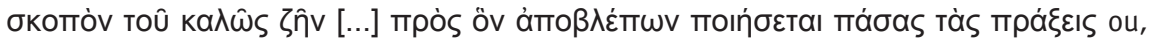
como quer KENNY (2011, p. 4), “set up for himself some object for a noble life [...] with a view to which he will govern all his conduct", pode ser interpretado no sentido sugerido,

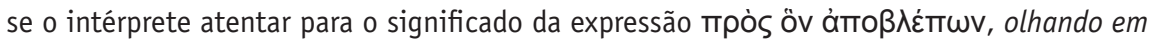
sua direção de modo resoluto. Assim, ao contemplar a ordem e repouso do deus, o homem

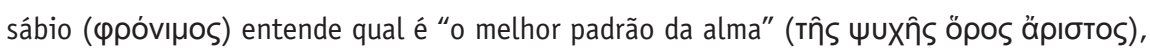

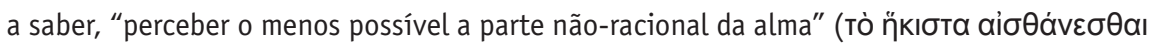




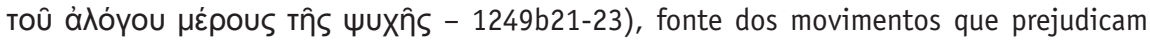
o seu repouso. Esse homem então percebe "aquilo em que consiste o bem viver" ( $\dot{\varepsilon} v$ Tívı

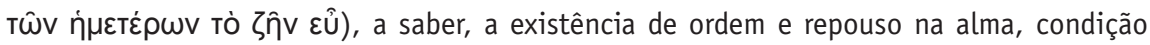
caracterizada pelo exercício das virtudes éticas coordenado pela sabedoria, bem como 0 exercício da contemplação. Em outras palavras, ele organiza a sua vida tendo observado resolutamente o deus. Ele também percebe “aquilo sem o qual não é possível ao homem

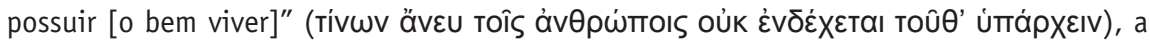
posse das coisas boas por natureza na medida certa em que não "impede servir o deus e

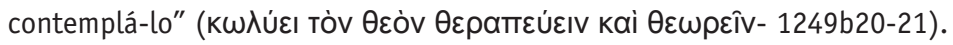

1 Para o argumento filológico a respeito da pertença dos livros comuns à Ethica Eudemia ver especialmente os capítulos 4, 5 e 6 de KENNY (1978, p. 70-160). Para o argumento filosófico sobre a superioridade da Ethica Eudemia frente à Ethica Nicomachea ver o argumento geral de KENNY (1992).

2 Uma breve explicação para facilitar a compreensão do leitor: optou-se por manter o texto de Kenny em inglês, uma vez que é a própria tradução o objeto de análise; o texto em inglês é acompa-nhado do original grego pra evitar que o leitor precise recorrer às edições da OCT para compreender o argumento da resenha; trechos de Aristóteles em português são obra do autor da resenha e ocorrem quando a tradução inglesa desses trechos não é objeto da análise, tais trechos integrando o argumento do autor da resenha referente à tradução inglesa de outros trechos.

3 ROSS (1998) verte oîs á $\lambda \eta \theta \varepsilon \dot{\varepsilon \varepsilon ~ p a r a ~ " t h e ~ s t a t e s ~ b y ~ v i r t u e ~ o f ~ w h i c h ~[t h e ~ s o u l] ~ p o s s e s s e s ~ t r u t h " . ~}$ A tradução espanhola de BONET (1993) opta por "las disposiciones por las cuales [el alma] posee la verdad”. DIRLMEIER (1957) propõe a tradução mais curiosa: "die Grundformen, durch wel-che [die Seele] [...] die Erkenntnis des Richtigen vollzieht”.

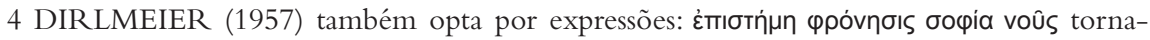
-se "wissenschaftliche Erkenntnis, praktische Einsicht, philosophische Weisheitund, intuitiver Verstand".

5 KENNY (2011, p. 168) comenta essa distinção: “a palavra grega 'episteme' é o substantivo equivalente à palavra grega mais comum para 'conhecer'. Aristóteles frequentemente o emprega nesse sentido geral, mas aqui e em outros tratados ele emprega um sentido estrito que significa conhecimento sistemático ou científico".

6 KENNY (2011, p. 169) comenta: “a palavra grega 'phronesis' é frequentemente traduzida como 'sabedoria prática', mas o adjetivo é supérfluo: sabedoria diz respeito antes à vida do que à teoria”.

7Ver 1141 a17-18 "é preciso ao homem de entendimento não apenas saber aquilo que decor-

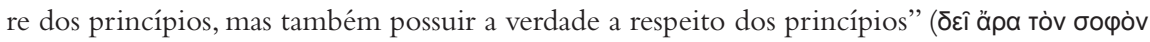

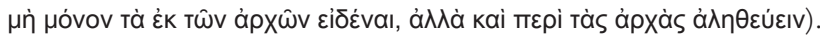

